\title{
COMPETÊNCIAS GERENCIAIS (ESPERADAS VERSUS \\ PERCEBIDAS) DE PROFESSORES-GESTORES DE \\ INSTITUIÇÕES FEDERAIS DE ENSINO SUPERIOR: \\ PERCEPÇÕ̂ES DOS PROFESSORES DE UMA \\ UNIVERSIDADE FEDERAL
}

\author{
MANAGERIAL COMPETENCES (EXPECTED VERSUS \\ PERCEIVED) OF ACADEMIC-MANAGERS \\ OF FEDERAL HIGHER EDUCATION INSTITUTION: \\ PERCEPTIONS OF TEACHERS FROM A FEDERAL UNIVERSITY
}

Avaliado pelo sistema double blind review
Editora Científica: Claudia Stadtlober
DOI 10.13058/raep.2016.V17n3.344

\section{MILKA ALVES CORREIA BARBOSA* milka.correia@gmail.com}

UNIVERSIDADE FEDERAL DE ALAGOAS

JOSÉ RICARDO COSTA DE MENDONÇA

UNIVERSIDADE FEDERAL DE PERNAMBUCO

\section{FERNANDA RODA DE SOUZA ARAÚJO CASSUNDÉ}

UNIVERSIDADE FEDERAL DO VALE DO SÃO FRANCISCO

\begin{abstract}
RESUMO
Este trabalho analisou as competências gerenciais (competências esperadas e competências percebidas) associadas ao papel de professor-gestor em universidades federais à luz do modelo proposto por Mendonça et al. (20I2). Argumenta-se que o papel social de professor-gestor é composto pelas competências gerenciais, que, em alguns asectos, são diferentes daquelas exigidas em outras facetas do papel de professor do Ensino Superior. O estudo foi de abordagem qualitativa e os dados foram coletados por meio de entrevistas semiestruturadas com professores-gestores da Universidade Federal do Vale do São Francisco (Univasf). A análise de conteúdo, com o suporte do software Atlas.ti, foi adotada para análise dos dados. As competências gerenciais esperadas indicaram aproximação com os componentes cognitivo, comportamental, ético e político assinalados por Mendonça et al. (20I2) para os saberes de gestão. Sobre as competências gerenciais percebidas, os entrevistados acreditam possuir aquelas caracterizadas por componentes políticos, interpessoais e éticos. Acredita-se que os resultados desta pesquisa possam contribuir com o entendimento sobre as competências dos professores-gestores de instituições federais de ensino superior.

Palavras-chave: Professor-Gestor; Competências gerenciais esperadas; Competências gerenciais percebidas; Instituição de Ensino Superior.
\end{abstract}

\section{ABSTRACT}

This work aimed to analyze the expected and perceived managerial skills associated with the role of academic-manager in federal universities, from the perspective of the model proposed by Mendonça et al. (2012). It is argued that the social role of academic-manager is composed of managerial skills, which are, in some respect, different from those required by other aspects of the role of professor. The study adopted a qualitative approach, with semi-structured interviews with academic-managers of the Federal University of the São Francisco Valley (UNIVASF). Data from the interviews were analyzed through content analysis, with the support of the Atlas.ti software. Expected managerial skillspoint to a proximity to the cognitive, behavioral, ethical and political components of managerial knowledge indicated by Mendonça et al. (2012). About the perceived managerial skills, respondents believe they have those characterized by political, interpersonal and ethical components. It is believed that the results of this research can contribute to the understanding of the competences of academic-managers of federal higher education institutions (FHEI).

Keywords: Academic-manager; Expected management competences; Perceived managerial competences; Higher Education Institutions. 


\section{INTRODUÇÃO}

O contexto do trabalho no Ensino Superior tem sofrido transformações significativas, nas últimas décadas, decorrentes tanto de mudanças econômicas e sociais quanto tecnológicas, que levam os diversos atores envolvidos nesse campo a empreenderem modificações estruturais e comportamentais.

Grandes forças, como a globalização e as transformações no modo de produção capitalista (do fordismo à acumulação flexível), fazem parte de um novo cenário que demandou reformas educacionais com o intuito de formar força de trabalho adequada às exigências do capitalismo (SANTIAGO; CARVALHO, 20II).

No âmbito da educação superior, a profissão de professor tem passado por revisões e mudanças. Houve alterações no trabalho do professor, ampliandose as atividades comumente associadas a esses profissionais, notadamente a docência, a pesquisa, a extensão, em virtude do aprofundamento da cultura do desempenho, que denota a supervalorização do conhecimento como nova forma de acumulação de capital.

Neste cenário, a concepção do professor de Ensino Superior como portavoz "soberano" de um saber dogmatizado, com habilidades para transmitir seus saberes, parece não mais corresponder ao perfil desse profissional exigido pelas instituições e pela sociedade em geral. Outras funções têm sido agregadas, tornando o exercício profissional do professor de Ensino Superior ainda mais complexo (ZABALZA, 2007; MUSSELIN, 20II; 20I3). Nesse sentido, "a auréola de cientistas iluminados, de especialistas na área, a qual, com frequência, está sob a figura dos professores da universidade” (ZABALZA, 2007, p. II4) é pouco para enfrentar os novos desafios que se apresentam a esses indivíduos.

Sabe-se que dentro de uma instituição de ensino superior (IES) o professor assume diferentes papéis sociais, sendo os mais centrais o de docente, o de pesquisador, o de extensionista e o de gestor, comumente reportados na literatura especializada (KERR, I982; ÉSTHER, 2007; POTGIETER; BASSON; COETZEE, 20II; MUSSELIN, 20II; 20I3). 


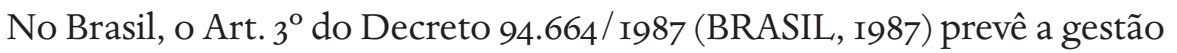
universitária como uma atividade própria do professor do Ensino Superior, juntamente com o ensino, a pesquisa e a extensão. Dessa forma, quando o professor atua na gestão, quer seja como reitor, pró-reitor, diretor de unidade, chefe de departamento, coordenador de curso, quer seja temporária ou permanentemente, entra em cena um papel específico, o de professorgestor (academic manager), "uma espécie particular de gerente, [....] eles possuem funções e papéis peculiares ao mundo acadêmico, na medida em que são, antes de tudo, em geral, professores de carreira” [....] (ÉSTHER; MELO, 2008, p.I7). Mesmo assumindo a posição de dirigente, esse indivíduo não deixa de ser professor (ÉSTHER, 2007) e, portanto, a multiatividade constitui-se no cerne do papel de professor-gestor (MILLER, I99I).

Aqui se demarca um aspecto relevante para essa argumentação, qual seja, a especificidade do trabalho gerencial em instituições de ensino superior (IES). Ao caracterizar o papel gerencial, Hill (2003) descreve-o como s complexo, constituído de tensões e ambiguidades, submetendo o sujeito a uma rotina de pressão, agitação e fragmentação.

Essa realidade evoca a noção de papel social, que é um pressuposto fundamental neste trabalho. Tendo por inspiração autores interacionistasconstrutivistas como Berger e Luckmann(2005) e Goffman(2009), neste estudo, o papel social é entendido como conjunto de atividades, comportamentos e práticas característico de uma dada situação social que resulta de um processo contínuo de construção social e que é desempenhado pelo sujeito em grupos de onde se originam expectativas e sob os quais ele exerce influência.

É possível ainda afirmar que o papel tem duas dimensões, a saber: uma convencional (que é partilhada pelos indivíduos) e uma idiossincrática (composta pelas interpretações distintas que os indivíduos têm sobre o papel (McCALL; SIMMONS, 1978). Partindo desse entendimento, admite-se que professores-gestores compartilham atividades, expectativas, competências gerenciais, apesar dos diferentes ambientes institucionais em que se

1 Autores como Whitchurch (2007), Deem, Hillyard e Reed (2007) e Musselin (2013) referem-se a esse sujeito e seu papel na gestão universitária. 
encontram ou de suas histórias individuais. Ou seja, o professor-gestor de uma instituição de ensino superior estabelece interações e relações com outros indivíduos e grupos, mantendo similaridades e diferenças quanto às competências gerenciais esperadas, às expectativas sobre seu desempenho no papel e aos desafios com os quais se deparam no cotidiano organizacional, por exemplo.

Argumenta-se, ainda, que o papel social de professor-gestor é, em certa medida, composto das competências gerenciais esperadas desses sujeitos, que, em alguns aspectos, são diferentes das competências profissionais exigidas no papel de docente ou de pesquisador. Nesse sentido, como mostraram Paiva e Melo (2009), há necessidade de mobilização de diversas competências profissionais por parte do professor de Ensino Superior para sua efetividade ao desempenhar diferentes papéis, inclusive no que diz respeito ao que as autoras chamaram de "atividades administrativas e burocráticas", relacionadas à função gerencial.

Demarca-se aqui outra premissa fundamental da argumentação neste estudo: o papel de professor-gestor contribui para a definição de competências gerenciais. Pressupõe-se, assim, que é possível identificar as competências gerenciais frequentemente associadas tanto ao papel quanto ao grupo de professores-gestores e, desse modo, auxiliar esses sujeitos em sua atuação nas atividades de gestão universitária, minimizando a ambiguidade e o conflito de papéis, em conformidade com Aziz et al. (2005).

De fato, os papéis atribuídos aos gestores comportam três aspectos do trabalho desses sujeitos: o que se espera que eles façam (definição do papel ou papel esperado), como eles interpretam e constroem o seu papel (papel percebido) e o que eles realmente fazem no decurso do seu trabalho (comportamento ou performance no papel - papel realizado) (HALES, 2005). Entende-se que tais facetas mantêm aproximações e afastamentos e que o alinhamento exato entre os três tipos é algo pertencente ao campo das ideias, dificilmente alcançado na realidade das organizações, havendo, provavelmente, um hiato entre o papel esperado, o papel percebido e o papel realizado, com possibilidades de conflitos e frustrações, resultantes das diferenças nestes três tipos. 
Posto isso, destaque-se o caráter inovador deste trabalho baseado na proposição de algumas aproximações teóricas entre papel social de professorgestor e competências gerenciais:

a. o papel esperado comporta as competências gerenciais esperadas²para indivíduos em determinadas posições sociais;

b. o papel percebido e as competências gerenciais percebidas emergem do julgamento do professor-gestor, e de terceiros (seus pares, chefias, corpo discente e demais públicos com os quais ele lida no seu cotidiano laboral). Considerando-se esses aspectos introdutórios, o presente trabalho teve como objetivo analisar as competências gerenciais (competências esperadas e competências percebidas) associadas ao papel de professor-gestor em universidades federais, à luz do modelo proposto por Mendonça et al. (20I2).

2 Correspondem ao que Paiva et al. (2013; 2014) referiram como competências ideais (ou exigidas). 


\section{O PAPEL DE PROFESSOR-GESTOR (ACADEMIC MANAGER)}

Uma clara distinção entre os papéis desempenhados por professores dificilmente pode ser encontrada, tendo em vista a proximidade e imbricação entre eles:

Em áreas como a educação continuada, transferência de tecnologia e programas especiais de acesso para os mais desfavorecidos, não há separação fácil entre seus aspectos intelectual e administrativo. Valores acadêmicos e a prática gerencial foram conjugados em combinações inusitadas e voláteis. (WHITCHURCH, 2007, p. 15).

Tome-se, por exemplo, a questão do desenvolvimento profissional, que pode ser visto como uma preocupação tanto do papel de gestor quanto do papel de professor ou de pesquisador. $\mathrm{Ou}$, ainda, a busca por editais e fundos que pode ser assumida tanto como parte do papel de pesquisador quanto do de gestor. Assim, com a clássica divisão entre academia e administração tornando-se menos nítida, ganharam destaques novos alguns profissionais que transformaram as IES, e, em especial, a universidade, em organizações multiprofissionais (WHITCHURCH, 20I2) 3 $^{3}$, entre eles, os professores-gestores (academic managers), aqueles professores que atuam em papéis de gestão.

Em termos amplos, o trabalho gerencial refere-se àquele que pessoas ou grupos executam quando em funções gerenciais e administrativas, incluindo atribuições e papéis (CAMPOS et al., 2008), o que envolve preocupar-se, principalmente, com a tomada de decisão; lidar com a imprevisibilidade, a interação humana, o intuitivo, o irracional e o ilógico (MOTTA, I997). Entretanto, no ambiente de IES, verificam-se, desde logo, algumas peculiaridades.

Primeiramente, pode-se afirmar que a função gerencial em IES coloca os professores frente a desafios e ambivalência como a escolha entre o trabalho acadêmico e o administrativo (ASKLING; HENKEL, 2000). Autores como

3 Whitchurch (2007) lembra ainda que, ao longo dos últimos anos, tem havido aumento do tráfego em toda a divisão administrativo-acadêmica. Alguns acadêmicos moveram para a administração e muitos administradores foram buscando graus acadêmicos mais altos. 
Santiago et al. (2006) e Amaral (2008) parecem concordar que professores-gestores vivenciam ambivalência, sentindo-se divididos entre as demandas gerenciais da administração central e os interesses locais de suas unidades, levando alguns deles a ver essa situação como contraditória e fonte de conflito de papel.

Por isso, alguns professores chegam a fazer distinção entre estar e ser dirigente, como se estivessem defendendo a si mesmos, visto que os significados do papel de gestor são muitos e estão associados a autoritarismo, coerção, falta de respeito com os acadêmicos, obsessão por eficiência, produtividade e custos. Assim, professores-gestores podem ser vistos como nativos, se apoiam os interesses dos colegas acadêmicos, ou como gerencialistas, se seguirem uma linha mais corporativa (WHITCHURCH, 2007). Em tal contexto, o papel de professor-gestor contempla expectativas internas e externas, conflitos, demandas e ideologias que por vezes mostramse incompatíveis ou contraditórios.

Outra demanda direcionada aos professores-gestores em IES refere-se ao alcance das expectativas de que esses indivíduos compreendam e aceitem novas responsabilidades e atividades, bem como aprendam a lidar com os mais diversos desafios da atividade gerencial. No mundo acadêmico, em especial nas IES, é comum somarem-se às atividades de ensino, pesquisa $\mathrm{e}$ extensão as atividades de gestão universitária, e, portanto, muito raramente o professor abre mão de suas atividades tidas como principais para dedicar-se mais exclusivamente às funções de gestor (SILVA, 20I2).

É possível detectar atribuições-chave que caracterizam a atuação dos professores-gestores, entre as quais, incluem-se influenciar políticas institucionais e procedimentos; recomendar acadêmicos para cargos e mandatos; controlar orçamento, turmas e avaliação docente e discente, entre outros, sendo, portanto, um papel que incorpora substancial poder e responsabilidade (CARROLL; WOLVERTON, 2004).

$\mathrm{Na}$ ótica de Silva e Cunha (20I2), professores em cargos de dirigentes vivenciam um processo de passagem deixando de ser responsáveis apenas por suas atividades e tarefas específicas, passando também a exercer influência sobre as atividades de várias pessoas, possuindo uma agenda imprevisível e dependente de necessidades alheias (SILVA; CUNHA, 20I2). 
De fato, os professores-gestores desempenham papéis complexos e distintos nas instituições de ensino superior, tais como o de atender às necessidades de vários atores, incluindo estudantes, pares, sociedades, membros de colegiados, entre outros. Além disso, eles estão engajados no desenvolvimento da IES, preocupados com a alocação de recursos limitados, preparando planos estratégicos e mediando conflitos (CARROLL; WOLVERTON, 2004).

No tocante aos papéis e às habilidades esperados do professor-gestor no nível estratégico, para Land (2003), esse sujeito deve ter habilidades interpessoais para construir comunicação entre a IES e suas instâncias internas e externas; deve desempenhar o papel de mediador; deve possuir habilidades para construção de grupos; deve promover a missão e as estratégias operacionais da Instituição. Ademais, espera-se que ele tenha valores morais e integridade pessoal e conheça o arcabouço legal que envolve e afeta a educação superior (LAND, 2003).

No âmbito das instituições federais de ensino superior (Ifes), o trabalho de Ésther (2007) mostrou que se espera que o reitor seja o representante da ideologia e dos valores da Ifes, "uma espécie de guardião e gestor da filosofia e identidade institucionais" (ÉSTHER, 2007, p.53), que deve atender a interesses de vários grupos. Já a pesquisa de Campos et al. (2008), também realizada em uma Ifes, descreve que a figura do pró-reitor está associada a dois papéis principais: o político e o gerencial. No caso do primeiro, inclui a manutenção de contatos de ligação, atuação como figura de proa e portavoz com capacidade de relações públicas. No segundo, espera-se que ele seja administrador de conflitos, amigo, administrador das competências dos outros, líder na proposição de ideias, ser elo entre a sociedade e a instituição, além de ser suporte para os diretores de centro e departamentos acadêmicos.

Para Potgieter, Basson e Coetzee (20II), chefes de departamento têm pelo menos quatro papéis: o acadêmico, o administrativo, o de liderança e o gerencial. Essa multiplicidade de papéis já estava presente no trabalho de Kerr (1982), que descreve o reitor como uma personagem de muitas faces, que deve olhar em diversas direções, evitando excluir qualquer grupo importante. 
Ao ter como base essas descrições, percebe-se que o papel de gestor se caracteriza pela complexa tarefa de fomentar, incentivar e gerenciar os mecanismos de desenvolvimento organizacional, sem deixar de considerar as atividades relacionadas ao tripé ensino, pesquisa e extensão. Para tanto, tais gestores precisam não somente de formação técnica, mas também do desenvolvimento de competências gerenciais, visto que há diferença entre tarefas administrativas e tarefas docentes, e para ambas se fazem necessárias competências profissionais específicas.

Na seção seguinte, discute-se acerca dos estudos que vêm reforçando a importância das competências gerenciais para o desempenho do papel de professor-gestor. 


\section{COMPETÊNCIAS GERENCIAIS DE PROFESSORES DE ENSINO SUPERIOR}

Com as recentes reformas educacionais brasileiras, novos conceitos e noções emergiram, formando um quadro de referências que norteiam as práticas de formação e de atuação docente (MURARI; HELAL, 2009). Entre essas referências estão o reconhecimento do professor como profissional e os atributos que delineiam a nova profissionalidade docente, com destaque para a noção de competências.

Destaque para a Lei de Diretrizes Básicas da Educação (LDB), que trouxe implicações diretas e indiretas para o professorado desse nível de ensino, como a apresentação de demandas às instituições de ensino em termos de composição, publicação e qualificação do corpo docente e a discussão sobre competências profissionais (PAIVA, 2007).

No presente estudo, toma-se como referência o conceito de competência profissional proposto por Paiva e Melo (2008), segundo o qual se trata de "mobilização de forma particular pelo profissional na sua ação produtiva de um conjunto de saberes de naturezas diferenciadas (que formam as competências intelectuais, técnico-funcionais, comportamentais, éticas e políticas)", que gera "resultados reconhecidos individual (pessoal), coletiva (profissional), econômica (organização) e socialmente (sociedade)" (PAIVA; MELO, 2008, p. 360). Nessa definição, percebe-se a natureza contextual, provisória e contingencial da competência, cujos resultados dependem das circunstâncias das entregas (DUTRA, 2004).

Importa ainda esclarecer que aqui se entende que competência pressupõe ação, comportamento efetivo e observável, e contextos permeados por variáveis específicas, semelhante ao que foi apontado por Resende (2000, p. 32), para o qual, competência trata da "transformação de conhecimentos, aptidões, habilidades, interesse, vontade etc. em resultados práticos”.

Por essa perspectiva, a competência assume caráter coletivo (PAIVA et al., 20I3). Ou seja, observações individuais e de outros atores permitem ao sujeito refletir sobre como sua competência contribui para a efetividade do trabalho e como ela poderia ser aperfeiçoada; tratando-se de uma reflexão 
sobre a ação conforme os moldes delineados por Schön (1983) e apropriados por Cheetham e Chivers (1996, 1999, 2000). No caso de professores, tais competências e seus respectivos resultados são valiosos para eles próprios, para alunos, pares, pessoal de apoio, instituição, Estado, enfim, para os outros atores sociais com os quais interagem.

Ao considerar o professor de Ensino Superior um ator que representa papéis, em diferentes âmbitos, é factível admitir que esse sujeito possa atuar como docente, gestor ou pesquisador. Em cada cenário específico, competências diferentes podem emergir, pois é provável que não se encontre uma competência única adequada à atuação em todos os contextos imagináveis.

Nessa perspectiva, acredita-se que o professor de Ensino Superior que almeja pela aprendizagem do aluno, pelos resultados de pesquisa e extensão, pela eficiência e eficácia na gestão organizacional, mobilizará competências profissionais diferenciadas, tais como as competências gerenciais.

Observa-se que o tema de competências gerenciais tem transitado entre o ambiente acadêmico e os mais diversos ambientes organizacionais, como as instituições de ensino superior. Brandão (2009) ressalta que tais competências constituem uma categoria que tem despertado crescente interesse por parte de teóricos, profissionais de mercado e pesquisadores, na medida em que exercem influência sobre a atuação de equipes de trabalho e sobre os resultados organizacionais.

As competências gerenciais estão inclusas nas competências individuais e referem-se ao conjunto de capacidades desenvolvidas pelo gerente, que são articuladas e mobilizadas conforme diferentes situações, necessidades ou desafios, viabilizando o alcance das estratégias organizacionais. São "aquelas que se pretende que coloquem as propostas e projetos organizacionais e funcionais (áreas) em ação" (RUAS, 2005, p. 48).

Dutra (2004) lembra que não basta o indivíduo possuir determinadas competências; é preciso averiguar também sua capacidade de entrega. Desta forma, "competência gerencial deve ser pensada como uma ação por meio da qual se mobilizam conhecimentos, habilidades e atitudes pessoais e profissionais a fim de cumprir com certa tarefa ou responsabilidade, numa determinada situação" (RUAS, 2005, p. 49). 
Além disso, as competências gerenciais têm de dar conta dos desafios enfrentados por gestores/gerentes, que incluem os problemas de ordem financeira, de infraestrutura e de falta de mão de obra (MELO; LOPES; RIBEIRO, 20I3). Em se tratando das competências gerenciais específicas para docente de IES, é preciso compreender que elas não devem ser descoladas da lógica de funcionamento desse tipo de organização, que mistura elementos burocráticos e técnicos. Assim, pensar em competências gerenciais para professores do Ensino Superior, demanda, por exemplo, compreender que esses indivíduos vivenciam atividades multifacetadas que imbricam pesquisa, ensino e extensão, além da gestão (PAIVA; MELO, 2009).

Igualmente, convém ressaltar que as ambiguidades e singularidades da gerência "vão se refletir na competência gerencial, que traz consigo o saber fazer bem e fazê-lo de fato, e, dessa forma, cria uma relação técnica ligada à maneira de como o indivíduo executa ou como desenvolve seu papel" (PAIVA; FERREIRA, 20I3, p. 2II).

Para além dos moldes das instituições federais de ensino superior e considerando as competências associadas a dirigentes em diferentes modelos de gestão universitária, O'Connor e Carvalho (2014) apontam que as competências interpessoais, em especial, a escuta e a capacidade de tomar decisões compartilhadas, alinham-se ao modelo colegiado. Já no gerencialismo, as figuras do reitor e demais gestores em nível estratégico aproximam-se dos chief executive officers (CEOs) e as competências privilegiam a capacidade de lidar com aspectos financeiros, se sobrepondo àquelas relacionadas às inter-relacionais (CARVALHO; MACHADO-TAYLOR, 20II).

Em particular, no caso dos professores que ocupam cargos de reitor e pró-reitores nas instituições federais de ensino superior, a posse de competências gerenciais tem sido diretamente associada à capacidade para resolução de problemas, aproveitamento de oportunidades e atendimento de demandas sociais. Autores como Pereira e Silva (20II) argumentam que as competências gerenciais dos dirigentes podem ser entendidas como alternativa de enfrentamento das transições pelas quais vêm passando o Ensino Superior, em especial, as universidades federais.

Percebe-se que os modelos de competências gerenciais são propostas 
que apresentam um amplo escopo de reflexões sobre a formação gerencial com base na realidade individual e estratégia organizacional, fato esse que caracteriza uma visão processual do desenvolvimento de competência, diferenciando-se de construtos que priorizam a listagem de atributos que por si só não agregam valor à organização ou às pessoas (BITENCOURT, 2004).

Ancorado na realidade sociocultural brasileira, o Modelo de Competências Profissionais do Professor do Ensino Superior, proposto por Mendonça et al. (2012), baseou-se nos papéis atribuídos aos professores na docência, na pesquisa, na extensão, na orientação e na administração, no interior das instituições de ensino e considera as implicações das especificidades do contexto educacional na definição de competências profissionais diferenciadas.

Mendonça et al. (20I2) definiram conjuntos de saberes específicos para o professor de Ensino Superior, quais sejam, docência, pesquisa, extensão, de gestão, avaliativos, interpessoais e tecnológicos, associados às componentes específicas do modelo de competências profissionais de Paiva (2007), sendo esse último uma adaptação de Cheetham e Chivers (1996, 1999, 2000) às contingências organizacionais. Pode-se descrever os saberes previstos no modelo de Mendonça et al. (20I2) da seguinte forma:

I. Docência: domínio da cena na sala de aula (presencial e virtual); tradução dos conteúdos para a linguagem e o cotidiano dos alunos. Componentes principais: cognitivo e o funcional.

2. Pesquisa: domínio de abordagens, métodos e técnicas de pesquisa; respeito ao objeto de pesquisa. Componentes principais: cognitivo, funcional, comportamental e ético.

3. Extensão: promoção da aproximação da instituição de ensino em relação à sociedade ou parte dela focalizada nas ações extensionistas; mobilização de sujeitos. Componentes principais: funcional, comportamental e ético.

4. De gestão: mobilização de subordinados e pares rumo aos objetivos grupais e organizacionais; domínio de processos administrativos e burocráticos em nível meso e macro-organizacional. Componentes principais: cognitivo, comportamental, ético e político. 
5. Avaliativos: domínio de critérios e processos em nível micro, meso e macro-organizacional; capacidade analítica frente a informações; domínio de mecanismos de feedback. Componentes principais: cognitivo, funcional, ético e político;

6. Interpessoais: trânsito nas relações em nível individual e grupal; capacidade de desenvolver e manter empatia. Componentes principais: comportamental, ético e político;

7. Tecnológicos: domínio das tecnologias disponíveis na organização; domínio de tecnologias de informação e comunicação (TIC). Componentes principais: cognitivo e funcional.

Um pressuposto caro ao modelo, sedimentado em Cheetham e Chivers (1996; 1999; 2000), é a noção de que, para ser considerado competente, o profissional age de tal forma que seus resultados são avaliados por si mesmo e por terceiros. Dependendo dessa avaliação, sua ação é legitimada como competente, o que pode não acontecer sempre, daí a natureza contextual da competência profissional. Em ambos os casos (julgado competente ou não), o profissional reflete sobre sua ação, de modo a melhorá-la ou adequála ao que é esperado por si mesmo e pelos públicos com os quais ele lida. Assim, a legitimação das competências se dá a posteriori, ou seja, com base no desempenho que o professor apresenta, quer seja no ensino, na pesquisa, na extensão e/ou na gestão.

O Modelo de Mendonça et al. (2012) pode ser visualizado na Figura I. 


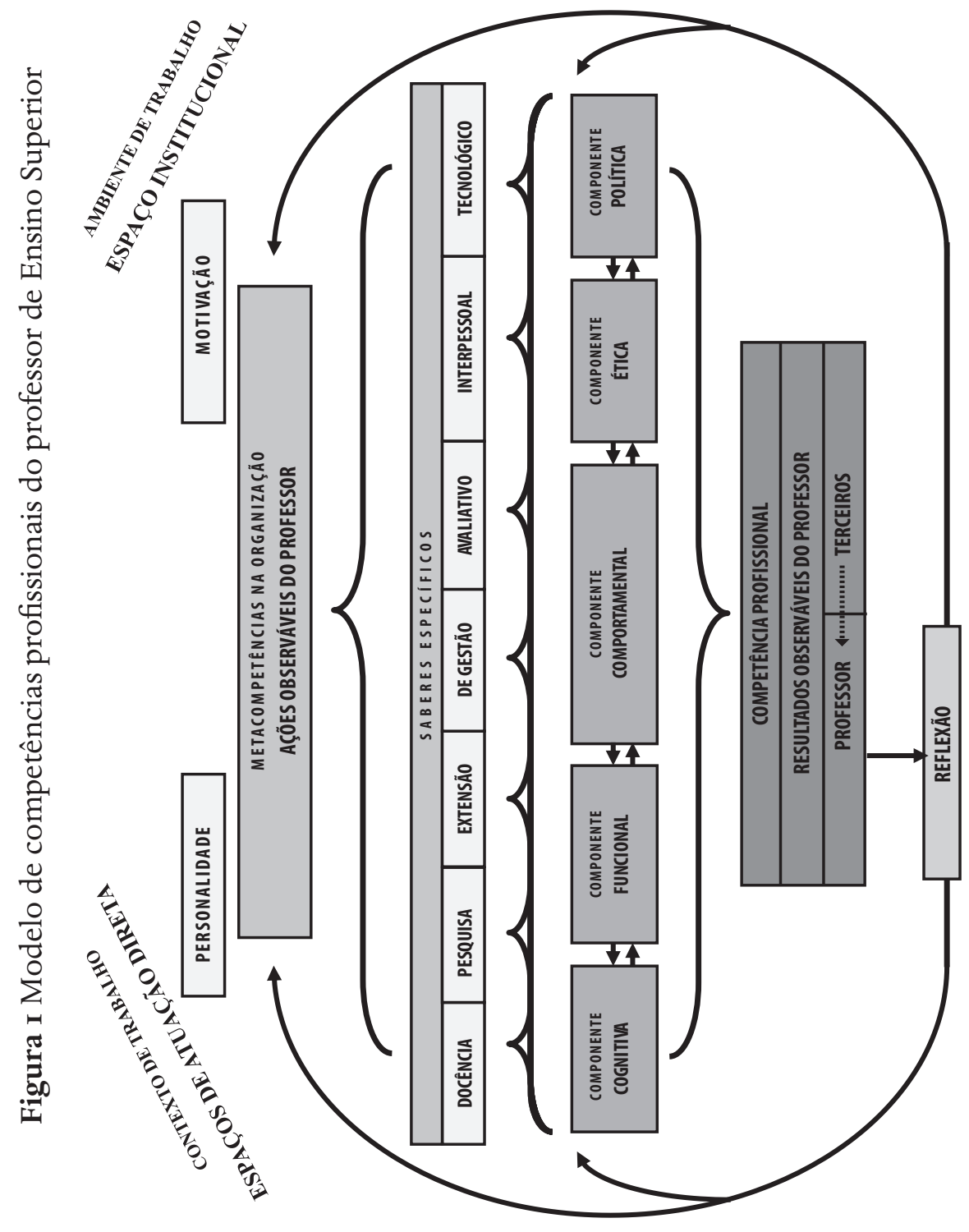

Fonte: Mendonça et al. (20I2, p. I2). 
Ainda sobre as potencialidades do modelo proposto por Mendonça et al. (20I2), saliente-se que ele leva em consideração os traços de personalidade e a motivação do professor, admitindo o processo de exteriorização, legitimação e reflexão do indivíduo acerca de suas competências professionais. Sendo assim, nesse modelo, reconhece-se que o contexto de trabalho do professor não se restringe à sala de aula, mas ultrapassa os limites da própria instituição de ensino, dependendo das atividades por ele realizadas, como é o caso dos professores-gestores.

Com efeito, o conhecimento sobre o perfil de competências, além de identificar possíveis tendências individuais de ação, serve de parâmetro para planejar programas de capacitação e para ajudar em decisões estratégicas. Atuando como sujeitos principais envolvidos na definição e alcance dos objetivos e metas da política pública de ensino, os professores-gestores das instituições de Ensino Superior não podem prescindir de competências gerenciais. 


\section{ASPECTOS METODOLÓGICOS}

O presente estudo adotou uma perspectiva predominantemente qualitativa, pois trabalhou com um nível de realidade que dificilmente pode ser quantificado e que procurou responder a questões muito particulares, específicas de um determinado contexto (MINAYO, 2004).

O campo empírico da pesquisa foi a Universidade Federal do Vale do São Francisco (Univasf), que é uma universidade pública federal vinculada ao Ministério da Educação (MEC), com sede na cidade de Petrolina, no sertão do estado de Pernambuco, nordeste brasileiro.

A criação da Univasf é resultado das políticas de expansão das universidades públicas e de interiorização do Ensino Superior, essa traz em seu bojo o compromisso com o desenvolvimento regional, por meio da apresentação de projetos e a realização de pesquisas que viabilizem soluções de problemas em organizações regionais (UNIVASF, 20I4).

Os dados foram coletados por meio de 22 entrevistas semiestruturadas, que foram tomadas como um evento de conversação capaz de "[...] enriquecer a prática de pesquisa e construir novas formas de conhecimento" (GODOI; MATTOS, 2010, p.302). Com o uso desta técnica, buscou-se fazer com que o entrevistado expressasse suas ideias, seus sentimentos e sua forma de pensar sobre as competências gerenciais esperadas e as percebidas do professorgestor. O número de entrevistas foi determinado com base na saturação teórica do tema. Assim, quando as respostas convergiram no sentido de que nenhum novo conceito ou categoria fosse acrescentado à análise, o processo de coleta de dados foi encerrado (FLICK; NETZ; SILVEIRA, 2004).

Foram entrevistados os indivíduos que constituem o grupo considerado relevante para o alcance do objetivo da pesquisa - os professores-gestores, escolhidos de acordo com o critério da tipicidade (GASKELL, 20I0). O grupo de respondentes foi formado de professores da Univasf que desempenham ou desempenharam o papel de gestor no nível estratégico da instituição, nos últimos io (dez) anos, ou seja, desde a fundação da IES até os dias atuais. Com o intuito de prover maior representatividade às informações levantadas, tomou-se a precaução de buscar participantes que já estiveram 
e outros que estão no papel de professor-gestor para alcançar extensão dos pontos de vista ou situações e evitar o custo de escolher apenas os casos que se enquadravam na perspectiva dos pesquisadores. No interesse da confidencialidade, letras e números foram usados para identificar a transcrição das falas dos professores-gestores (PG).

As categorias analíticas denominadas competências gerenciais esperadas e competências percebidas foram definidas a priori, e suas respectivas definições constitutivas (DC) e definições operacionais (DO) (VIEIRA, 2004) correspondem aos componentes definidos no modelo de Mendonça et al. (20I2).

Em crescente utilização e legitimação nos estudos qualitativos em Administração (MOZZATTO; GRZYBOVSKI, 20II), a análise de conteúdo (AC) foi o procedimento utilizado para análise dos dados com o apoio do software Atlas Ti. 


\section{COMPETÊNCIAS GERENCIAIS ESPERADAS E PERCEBIDAS DO PROFESSOR-GESTOR}

No Ensino Superior, as atividades de ensino, pesquisa, extensão, orientação de alunos e, também, as administrativas e burocráticas se mesclam no cotidiano do professor, exigindo-lhes competências diferenciadas (PAIVA; MELO, 2008). Tomando-se essa assertiva como ponto de partida, buscou-se identificar as competências gerenciais esperadas e percebidas associadas ao papel de professor-gestor.

No que tange às competências gerenciais esperadas - ou competências exigidas segundo Paiva et al. (2014), os sujeitos da pesquisa salientaram a complexidade e multiplicidade dessas, caracterizando-as por uma mescla semelhante aos componentes que Mendonça et al. (20I2) elegeram como sendo os principais para os saberes de gestão - o cognitivo, comportamental, ético e político.

Observou-se ainda que as competências gerenciais esperadas conservam elementos associados aos papéis de docente, pesquisador e de extensionista, pois, conforme os entrevistados, o papel de gestor não os tornam isentos aos demais.

Com base nas entrevistas, apresentam-se as competências gerenciais esperadas compiladas no Quadro I, ressaltando-se que se buscou reproduzir de forma mais literal possível as palavras dos participantes. Ao mesmo tempo, na análise, as competências apontadas pelos participantes foram associadas aos componentes (subcategorias) e grupos de habilidades (dimensões) previstos no modelo proposto por Mendonça et al. (2012), revelando a adequação desse aporte analítico à presente investigação. 
\& FERNANDA RODA DE SOUZA ARAÚJO CASSUNDÉ

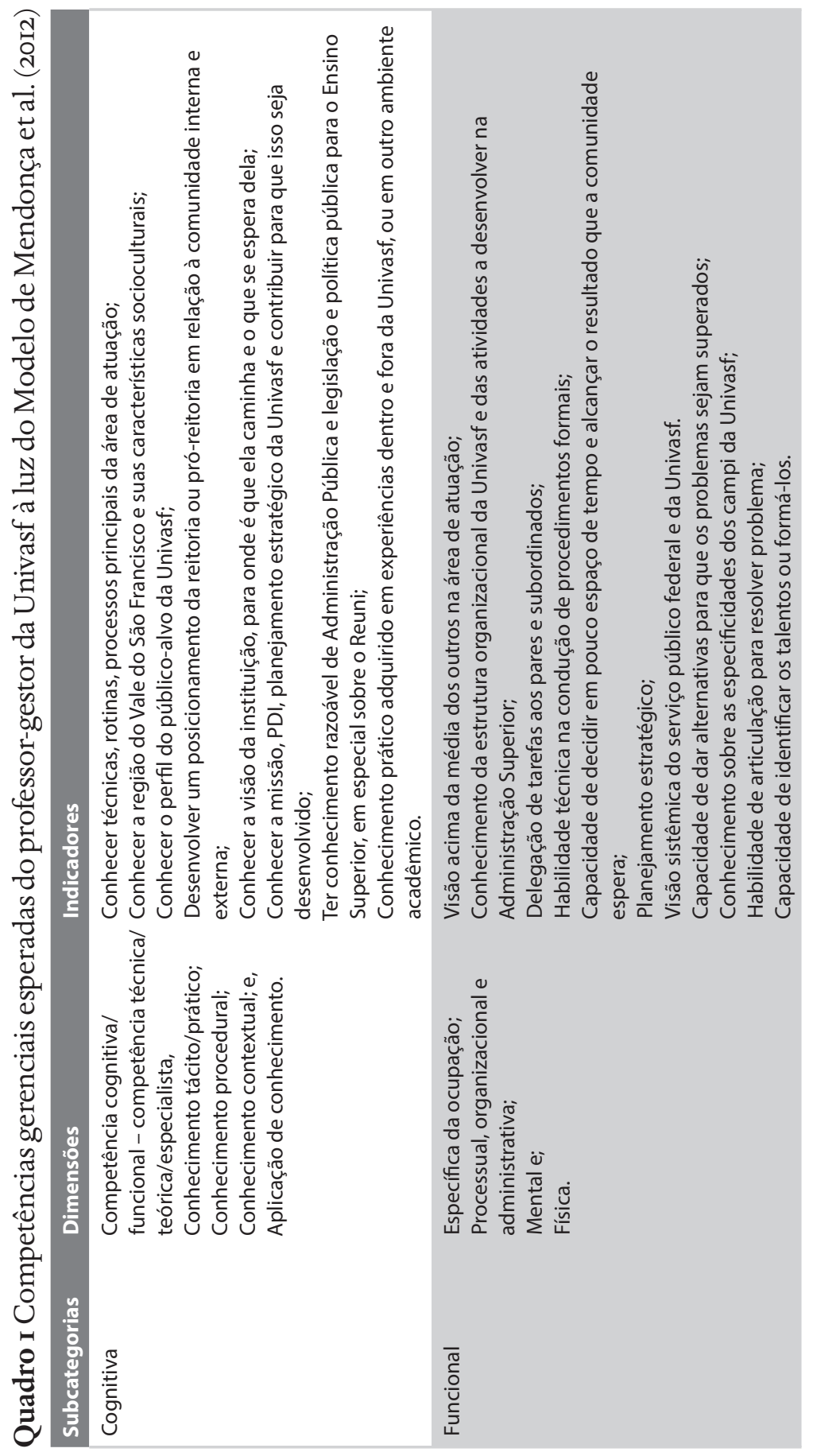


COMPETÊNCIAS GERENCIAIS (ESPERADAS VERSUS PERCEBIDAS) DE PROFESSORES-GESTORES DE INSTITUIÇÕES FEDERAIS DE ENSINO SUPERIOR: PERCEPÇÕES DOS PROFESSORES DE UMA UNIVERSIDADE FEDERAL

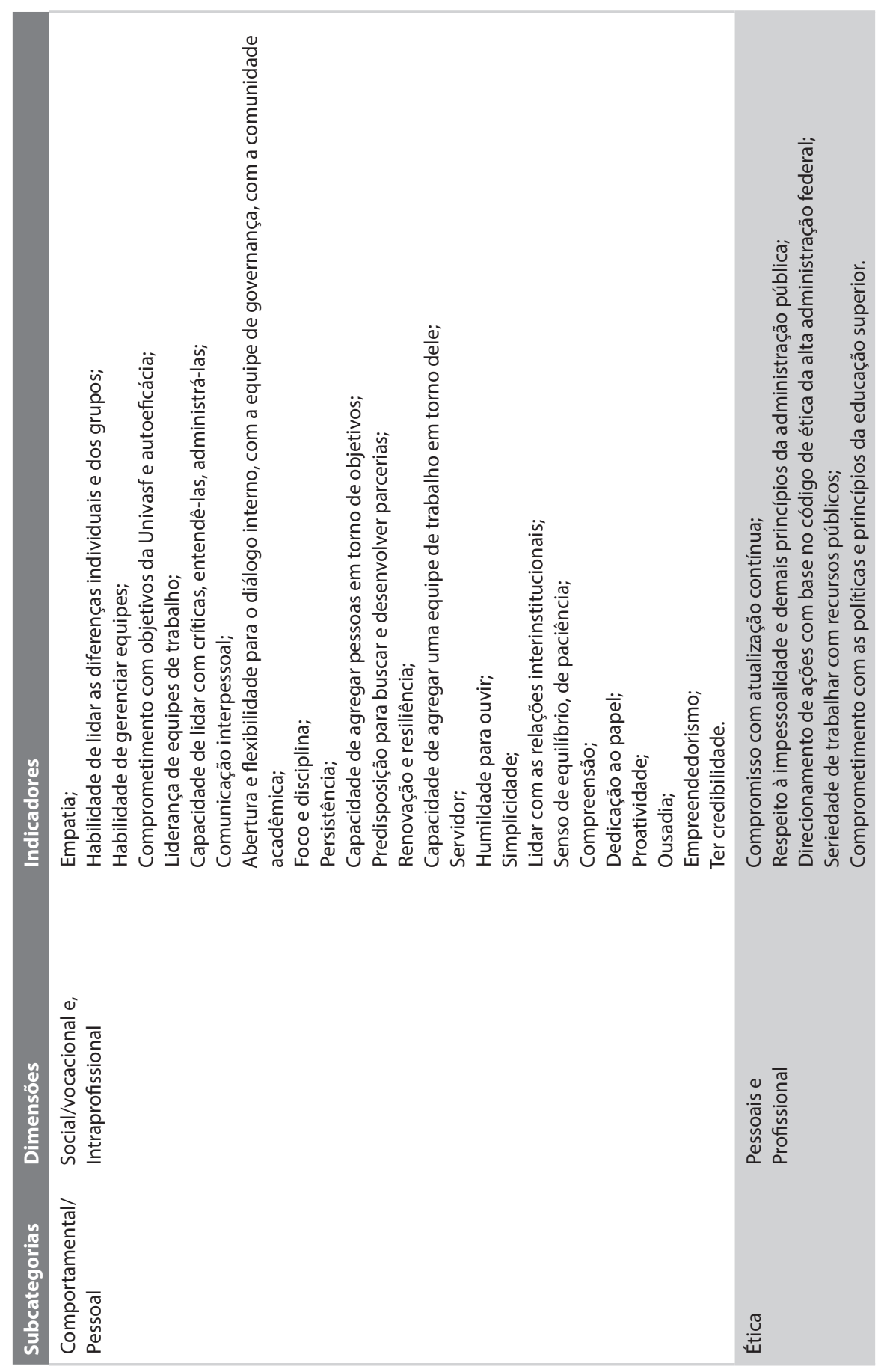


MILKA ALVES CORREIA BARBOSA, JOSÉ RICARDO COSTA DE MENDONÇA

\& FERNANDA RODA DE SOUZA ARAÚJO CASSUNDÉ

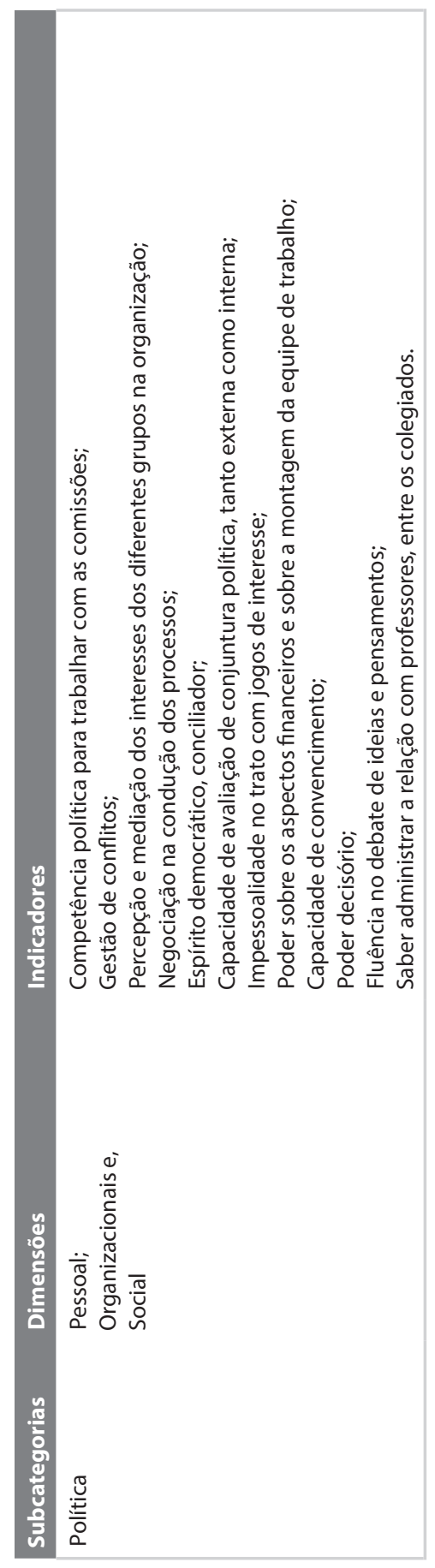


Note-se que as competências gerenciais esperadas destacadas pelos entrevistados da Univasf incluem os saberes de gestão do professor de Ensino Superior voltados à mobilização de subordinados e pares rumo aos objetivos grupais e organizacionais; domínio de processos administrativos e burocráticos em nível meso e macro-organizacional, correspondendo ao que Mendonça et al. (20I2) pressupuseram.

Entre os componentes previstos pelo modelo de Mendonça et al. (20I2), o componente comportamental recebeu ênfase nos relatos, indicando que os sujeitos centram as competências gerenciais esperadas em características individuais, o que, de certa forma, explica-se tendo em vista a incidência do processo de autodirecionamento (PAIVA, 2007). Em concordância, sobressaíram metacompetências relacionadas ao domínio do conhecimento específico e de metodologias, seguidas das habilidades pessoais e sociais.

As entrevistas também revelaram que, ao indicar as competências esperadas, os sujeitos se valeram de particularidades organizacionais da Univasf, indicando as contingências e aspectos socioculturais que influenciam suas competências gerenciais, corroborando-se, assim, mais uma dimensão do modelo proposto por Mendonça et al. (2012), qual seja, aquela que considera as implicações das especificidades do contexto educacional na definição de competências profissionais diferenciadas.

Ainda durante as entrevistas, surgiram expressões como "a minha experiência mostra como gestor"; "a minha trajetória na posição de gestor mostrou"; "aprendi no dia a dia como estou que essa competência é importante", usadas pelos professores entrevistados para justificarem o conjunto de competências gerenciais esperadas, indicando que as especificidades de sua área de atuação, sua formação, suas experiências anteriores, histórias de vida, trajetória acadêmica permeiam esse repertório de competências.

Esse ponto chama atenção, pois, com base em Dubar (2005), teoricamente presume-se que as competências esperadas sejam um desdobramento ou componentes do papel esperado de professor-gestor da Univasf. Entretanto os relatos dos participantes denotaram que a referência dos sujeitos da pesquisa, ao eleger as competências esperadas, orientou-se pela forma como eles percebem o papel de professor-gestor (papel percebido). 
As competências percebidas pelos professores-gestores da Univasf caracterizam-se pelos componentes políticos, interpessoais e éticos do modelo de Mendonça et al. (20I2), e segundo os sujeitos da pesquisa, são as mais relevantes para eles em seu cotidiano. Convergindo com os relatos dos professores entrevistados, os dados coletados durante a observação participante em reuniões do Fórum dos Pró-reitores e do Fórum Administrativo tais componentes (políticos, interpessoais e éticos) emergiram quando os gestores atuavam na mediação de conflitos entre níveis hierárquicos e coalizões distintas.

Em concordância com os componentes identificados nas competências percebidas, sobressaíram as metacompetências relacionadas ao domínio do de habilidades sociais e pessoais. O relato a seguir dá amparo a essa ponderação:

[...] uma coisa que eu tive que aprender ou desenvolver mais foi essa convivência com as diferenças. Que diferenças são essas? Na universidade, você tem diversos grupos de forças, de poder, e esses grupos ora um está no centro do poder, em uma posição de mando, estão com a bola e ora esse grupo perde essa posição de mando, mas eles continuam em todos os setores, aqueles que perderam e quando você assume um cargo como gestor você tem que gerenciar todos, independente das opções políticas, ideológica. Eu acredito que uma competência que eu tenho desenvolvido foi a de agregar as pessoas, chamar as pessoas para trabalhar em equipe, para trabalhar em grupo, claro com conflitos, brigas, com tudo que faz parte de gerenciar pessoa. PG5 - 37:37

Sabe-se que mesmo sem uma competência esperada, o indivíduo não necessariamente estará impotente frente a uma situação, pois, com conhecimentos gerais adquiridos anteriormente, ele pode tentar encontrar cursos de ação, ainda que torne o trabalho difícil e aleatório (PERRENOUD, 2013). Essa foi justamente a situação relatada pelos entrevistados: eles não ficaram paralisados ao perceber que não dispunham de competências inerentes ao papel de gestor; eles trataram de atuar com o repertório acumulado em sua trajetória pessoal e profissional na Univasf, o que os levou várias vezes a cometer erros que poderiam ter sido evitados.

Nesse sentido, os professores-gestores da Univasf reconheceram que desenvolveram competências muito distantes daquelas que eles mesmos 
apontaram como sendo competências esperadas e afirmaram que as Políticas Públicas (PP) e/ou as Políticas Organizacionais (PO) poderiam ajudá-los a desenvolver as competências gerenciais que ainda não possuem.

Diante disso, pôde-se perceber que, para esses indivíduos, a formação individual ou o desenvolvimento informal de competências gerenciais não exclui a necessidade de PP e PO de formação de professores-gestores para a gestão universitária. As falas a seguir exemplificam esse ponto de vista dos sujeitos:

Então eu acredito que o treinamento, a capacitação, podem fazer com que algumas habilidades mais técnicas, mais gerenciais sejam aprendidas, desde que você se disponha a aprender; esteja aberto ao novo. Quem acha que não precisa mais, não vai fazer efeito, mas quem se coloca numa posição de aprendiz, vai crescer muito. PG5 - 37:5

Como, eu só acredito no aprimoramento de competência né, é, com estudo né, com aplicação, fazer curso, se capacitar, então assim, eu não acredito, por exemplo, o autodidata né, ele tem uma limitação num é, é diferente PGI4 - 46:4 Após identificar as competências gerenciais esperadas e percebidas, caminhase para a as considerações finais do estudo. 


\section{CONSIDERAÇÕES FINAIS}

Em consonância com os aspectos expostos na introdução, esta investigação teve como objetivo analisar as competências gerenciais (competências esperadas e competências percebidas) associadas ao papel de professorgestor em universidades federais à luz do modelo proposto por Mendonça et al. (20I2).

Nesse sentido, pode-se afirmar que as competências esperadas indicadas pelos sujeitos da pesquisa descreveram quase o retrato de um "supergestor" para a Univasf , um professor-gestor com perfil idealizado de competências e características diversas impossíveis de serem possuídas por uma única pessoa, como alertaram Kerr (I982); Quintiere, Vieira e Oliveira (2012). Já as competências percebidas fizeram referência principalmente às ações e interações vivenciadas pelos próprios sujeitos e seus pares no espaço organizacional, corroborando o caráter inter-relacionai das competências referenciado por Melo, Lopes e Ribeiro (20I3) e Salles e Villardi (20I4).

Os dados da pesquisa também evidenciaram uma desarticulação entres os níveis individual, meso e macro-organizacional: de um lado, os professoresgestores percebem que há necessidade de formação de competências para os papéis que desempenham (inclusive o de gestor), mas, de outro, a estrutura da carreira de magistério superior em âmbito federal e as práticas de gestão de pessoas na Univasf parecem não estar coerentes com essas demandas. Tal como assinalou Amaral (2008), pouco reconhecimento e recompensas são dispensados às tarefas administrativas, apesar de, em alguns casos, elas representarem uma significativa porção de tempo de trabalho dos professores.

Este estudo oportunizou testar o modelo de Mendonça et al. (20I2) em um ambiente organizacional reconhecidamente singular - uma universidade federal, o que se acredita ter contribuído para a robustez teórica e comprovação empírica do modelo.

O processo de agrupar em classes de forma sistemática as competências gerenciais do professor-gestor se constitui em uma colaboração ao trabalho de Mendonça et al. (20I2). Assim, em um processo de reciprocidade, o 
modelo analítico e os dados obtidos na realidade empírica estudada se encontraram e trocaram contribuições, consolidando referenciais nacionais, com vista à inserção internacional na discussão sobre a gestão do Ensino Superior.

As competências esperadas identificadas no trabalho de campo podem também ser tomadas como subsídios, pela Univasf, para planejar momentos de preparação para professores que assumam cargos de direção. Assim, sugere-se aos formuladores de políticas organizacionais o engajamento em iniciativas para apreender mais sobre as feições emergentes do trabalho acadêmico, de forma a poder identificar os efeitos das políticas públicas nos professores e nos diferentes papéis que eles desempenham na Ifes, avaliando problemas que podem ser resolvidos com mudanças nas políticas em âmbito da instituição.

Ainda sob essa perspectiva, os achados da pesquisa se constituem em uma contribuição para a implantação das diretrizes da Política Nacional de Desenvolvimento de Pessoal (PNDP) da Administração Pública Federal, sobretudo aquelas relacionadas ao art. $\mathrm{I}^{\circ}$, inciso III, do Decreto 5.707/2006, que destaca a necessidade de se adequar as competências requeridas dos servidores aos objetivos das instituições públicas, tendo como referência o plano plurianual (BRASIL, 2006), no contexto das universidades federais.

Ao situar a temática da competência gerencial ao papel professor-gestor desempenhado pelo professor de Ensino Superior, na Universidade Federal do Vale do São Francisco (Univasf), a pesquisa proporcionou ainda a construção de conhecimento sobre uma realidade que precisa ser melhor investigada: papéis, atividades, desafios e tarefas com os quais mestres e doutores em início de carreira, lotados em universidades federais criadas nos últimos anos por meio do Programa de Reestruturação e Expansão das Universidades Federais (Reuni), deparam-se quando tentam operacionalizar a complexa missão do ensino, pesquisa e extensão (LIMA; VILLARDI, 20II; GUIMARÃES, 2013).

A opção por investigar o papel de gestor e respectivas competências gerenciais emergiu da necessidade de se estudar os professores de Ensino Superior para além das abordagens que tradicionalmente lhes atribuem 
os papéis de docente e de pesquisador (MUSSELIN, 20II). Nesse sentido, Whitchurch (2007) já mostrava a necessidade de desenvolver uma compreensão mais abrangente e completa sobre esses sujeitos, com ênfase em seu cotidiano e suas práticas no papel gerencial.

Em virtude das escolhas metodológicas e epistemológicas, toda e qualquer pesquisa possui suas limitações. Neste estudo em particular, destaca-se o fato de que, ao investigar-se as competências gerenciais de professores em uma única universidade federal, perde-se um pouco da amplitude que poderia ser alcançada ao ouvirem-se diversos indivíduos em diferentes IES. Por sua vez, com o estudo qualitativo básico, ganhou-se em termos de profundidade na medida em que se ouviu cada indivíduo em particular.

Como também, ao optar-se pelo maior detalhamento das percepções subjetivas dos professores-gestores do nível estratégico da Univasf, deixouse de ouvir os ocupantes dos demais cargos gerenciais, por exemplo, os coordenadores dos Colegiados Acadêmicos.

I. Visto que os terrenos político e profissional das IES são muito mais complexos do que as tradicionais categorias de análise organizacional podem explicar, entende-se que estudar organizações e atores do Ensino Superior como tópicos de gestão é uma avenida acadêmica promissora a ser explorada, sendo possível traçar algumas possibilidades de pesquisas futuras:

2. estudos comparativos entre IES públicas e privadas, entre níveis professores-gestores que atuam em níveis organizacionais diferentes numa mesma IES, por exemplo, entre reitores e diretores de centro, entre diretores de faculdades e coordenadores de curso; entre reitores e líderes de grupo de pesquisa, podem evidenciar variações nas competências gerenciais;

3. estudos de natureza quantitativa com a adoção de modelos como o de Quinn et al. (2003) podem revelar outros perfis ideais e reais de competências gerenciais associadas ao papel de professor-gestor;

4. estudos de natureza qualitativa para ouvir os professores, seus pares e outros atores institucionais acerca das competências gerenciais;

5. investigações com professores que atuam no papel de líder de grupo ou 
núcleo de pesquisa, tendo em vista as peculiaridades das atividades que envolvem esse sujeito, presentes no trabalho de Odelius et al. (20Ir);

6. propõe-se, ainda, pensar em construir modelo quantitativo que possa validar as subcategorias, dimensões e indicadores associados ao Modelo de Mendonça et al. (20I2) dotados na presente pesquisa.

Convém ressaltar que este trabalho não teve a pretensão de esgotar a discussão em torno dos construtos e das temáticas aqui tratados, mas dar contribuições para promover ensino, pesquisa, extensão e gestão em níveis de excelência nas IES, lançando luzes sobre os sujeitos que atuam no papel de professor-gestor e suas competências gerenciais. 


\section{REFERÊNCIAS}

AMARAL, A. Transforming higher education. In: AMARAL, A.; BLEIKLIE, I.; MUSSELIN, C. From Governance to Identity. London: Springer, 2008. p. 81-94.

ASKLING; B.; HENKEL, M. Higher education institutions. In: KOGAN, M. et al. Transforming higher education: a comparative study. London: Jessica Kingsley, 2000. p. 109130.

AZIZ, S. et al. Understanding the training needs of department chairs. Studies in Higher Education, Oxford, v. 30, n. 5, p. 571-59, 2005.

BERGER, P. L.; LUCKMANN, T. A construção social da realidade. 25.ed. Petrópolis: Vozes, 2005.

BITENCOURT, C. C. A gestão de competências gerenciais e a contribuição da aprendizagem organizacional. Revista de Administração de Empresas, v. 44, n. 1, p. 58-69, 2004

BRANDÃO, H. P. Aprendizagem, contexto, competência e desempenho. 2009. 363fls. Tese (Doutorado em Psicologia Social) - Universidade de Brasília, Brasília, 2009.

BRASIL. Decreto n 5.707, de 23 de fevereiro de 2006. Institui a Política e as Diretrizes para o Desenvolvimento de Pessoal da administração pública federal direta, autárquica e fundacional, e regulamenta dispositivos da Lei ${ }^{\circ}{ }^{\circ}$ 8.112, de 11 de dezembro de 1990. Brasília, DF: 2006.

BRASIL. Decreto $n^{\circ} 94.664$ de 8 de junho de 1987. Aprova o plano único de classificação e retribuição de cargos e empregos de que trata a Lei $\mathrm{n}^{\circ}$ 7.596, de 10 de abril de 1987. Disponível em: <http:/ / www.planalto.gov.br/ccivil_03/decreto/Antigos/D94664.htm>. Acesso em: 05/05/2013.

CAMPOS, D. C. S. et al. Competências Gerenciais Necessárias aos Professores-Gerentes que atuam em pró-reitorias: o caso de uma Instituição Federal de Ensino Superior de Minas Gerais. In: ENANPAD, 32., 2008, Rio de Janeiro. Anais... Rio de Janeiro: ANPAD, 2008.

CARROLL, J. B.; WOLVERTON, M. Who becomes a chair? In: W. GMELCH, W.; SCHUH, J.H. (Eds.). The life cycle of a department chair. New Directions for Higher Education, San Francisco, n. 126, p. 3-10, 2004.

CARVALHO, T.; MACHADO-TAYLOR, M. L. Senior Management in Higher Education. In: BAGILHOLE, B.; WHITE, K. (Eds.). Gender, power and management: A Cross-Cultural Analysis of Higher Education. Basingstoke: Palgrave Publishers, 2011. p. 90-109.

CASTRO, D.; TOMÀS, M. Development of Manager-Academics at Institutions of Higher Education in Catalonia. Higher Education Quarterly, v. 65, n. 3, p. 290-307, 2011.

CHEETHAM, G.; CHIVERS, G. A New Look at Competent Professional Practice. Journal of European Industrial Training, Bradford, v. 24, n. 7, p. 374-383, 2000. 
CHEETHAM, G.; CHIVERS, G. The reflective (and competent) practioner. Journal of European Industrial Training, Bradford, v. 22, n. 7, p. 267-276, 1999.

CHEETHAM, G.; CHIVERS, G. Towards a holistic model of professional competence. Journal of European Industrial Training, Bradford, v. 20, n. 5, p. 20-30, 1996.

DEEM, R.; HILLYARD, S.; REED, M. Knowledge, higher education and the new managerialism: The Changing Management of UK Universities. Oxford: Oxford University Press, 2007.

DUTRA, J. S. Competências: Conceitos e Instrumentos para a Gestão de Pessoas na Empresa Moderna. São Paulo: Atlas, 2004.

DUBAR, C. A socialização: construção das identidades sociais e profissionais. São Paulo: Martins Fontes, 2005.

ÉSTHER, A. B. A construção da identidade gerencial dos gestores da alta administração das universidades federais em Minas Gerais. 2007. 276fls. Tese (Doutorado em Administração) - Faculdade de Ciências Econômicas, Universidade Federal de Minas Gerais, Belo Horizonte, 2007.

ÉSTHER, A. B.; MELO, M. C. O. L. A construção da identidade gerencial dos gestores da alta administração de universidades federais em Minas Gerais. Cadernos EBAPE.BR, Rio de Janeiro, v. 6, n.1, p. 01-17, 2008.

FLICK, U.; NETZ, S.; SILVEIRA, T. Uma introdução à pesquisa qualitativa. 2.ed. São Paulo: Bookman, 2004.

GASKELL, G. Entrevistas individuais e grupais. In: BAUER, M. W.; GASKELL, G. Pesquisa qualitativa com texto, imagem e som: um manual prático. 8.ed. Petrópolis: Vozes, 2010. p. 64-89.

GODOI, C. K.; MATTOS, P. L. C. L. Entrevista qualitativa: instrumento de pesquisa e evento dialógico. In: GODOI, C. K; BANDEIRA-DE-MELLO, R.; SILVA, A. B. (Orgs.). Pesquisa qualitativa em estudos organizacionais: paradigmas, estratégias e métodos. São Paulo: Saraiva, 2010.

GOFFMAN, E. A representação do eu na vida cotidiana. 13.ed. Petrópolis: Vozes, 2009. GUIMARÃES, J. C. Gestão em IFES: as razões que determinam o doutor como gestor - Uma abordagem sob a perspectiva das competências individuais. Revista Eletrônica do Mestrado Profissional em Administração da Universidade Potiguar, v. 5, n. 2, p. 35-47, 2013.

HALES, C. Managerial roles. In: COOPER, C. L. The blackwell encyclopedia of management. 2.ed. Oxford: Blackwell Publishing, 2005.

HILL, L. A. Become a manager: How New Managers Master the Challenges of Leadership. 2.ed. Boston: Harvard Business School Press, 2003.

KERR, C. Os usos da universidade. Fortaleza: Edições UFC, 1982.

LAND, P. C. From de other side of the academy to academic leadership roles: crossing the great divide. New Directions for Higher Education, n. 124, p.13-21, 2003. 
LIMA, S. M. P.; VILLARDI, B. Q. Como gestores públicos de uma instituição federal de ensino superior brasileira aprendem na prática a desenvolver suas competências gerenciais. In: ENANPAD, 35., 2011, Rio de Janeiro. Anais.... Rio de Janeiro: ANPAD, 2011.

McCALL, G. J.; SIMMONS, J. L. Identities and Interactions: An examination of human associations in everyday life. 6. ed. New York: Free Press, 1978.

MELO, M. C. O. L.; LOPES, A. L. M.; RIBEIRO, J. M. O Cotidiano de Gestores entre as Estruturas Acadêmica e Administrativa de uma Instituição de Ensino Superior Federal de Minas Gerais. Revista Organizações em Contexto, v. 9, n. 17, p. 205-227, 2013.

MENDONÇA, J. R. C. de et al. Competências Profissionais de Professores do Ensino Superior no Brasil: proposta de um modelo integrado. In: FÓRUM DA GESTÃO DO ENSINO SUPERIOR NOS PAÍSES E REGIÕES DE LÍNGUA PORTUGUESA, 2., 2012, Macau, Anais... Macau: Instituto Politécnico de Macau, 2012.

MILLER, H. Academics and their Labour Process. In: SMITH, C.; KNIGHTS, D.; WILLMOTT, H. (Eds). White-Collar Work: the non-manual labour process. London: Macmillan, 1991, p. 109-137.

MINAYO, M. C. de S. O desafio do conhecimento: pesquisa qualitativa em Saúde. 8.ed. São Paulo: Hucitec, 2004.

MOTTA, P. R. Gestão Contemporânea. 8.ed. Rio de Janeiro: Record, 1997.

MURARI; J. M. F.; HELAL, D. H. O estágio e a formação de competências profissionais em estudantes de Administração. Revista Gestão e Planejamento Salvador, v.10, n. 2, p. 262280, 2009.

MOZZATTO, A. R.; GRZYBOVSKI, D. Análise de Conteúdo como Técnica de Análise de Dados Qualitativos no Campo da Administração: Potencial e Desafios. Revista de Administração Contemporânea, v. 15, n. 4, p. 731-747, 2011.

MUSSELIN, C. Redefinition of the relationships between academics and their university. High Education, n. 65, p. 25-37, 2013.

MUSSELIN, C. European universities' evolving relationships: the state, the universities, the professoriate. In: CHER CONFERENCE, Reykjavik, Iceland. Anais... Reykjavik: University of Twente, 2011.

O'CONNOR, P.; CARVALHO, T. Different or similar: constructions of leadership by senior managers in Irish and Portuguese universities. Studies in Higher Education, v. 40, n.9, p. 1-14, 2014.

ODELIUS, C. C. et al. Processos de aprendizagem, competências aprendidas, funcionamento, compartilhamento e armazenagem de conhecimentos em grupos de pesquisa. Cadernos EBAPE.BR, v. 9, n. 1, p. 199-220, 2011.

PAIVA, K. C. M. Gestão de competências e a profissão docente: um estudo de caso em universidades no Estado de Minas Gerais. 2007. 278 fls. Tese (Doutorado em Administração), Universidade Federal de Minas Gerais, Belo Horizonte, Brasil, 2007. 
PAIVA, K. C. M.; FERREIRA, L. S. Competências Gerenciais na área de Tecnologia de Informação. Revista Gestão \& Tecnologia, v. 13, n. 1, p. 205-229, 2013.

PAIVA, K. C. M.; MELO, M. C. O. L. Competências, gestão de competências e profissões: perspectivas de pesquisas. Revista de Administração Contemporânea, v. 12, n. 2, p. 339-368, 2008.

PAIVA, K. C. M.; MELO, M. C. O. L. Competências profissionais docentes e sua gestão em universidades mineiras. In: ENGPR, 2., 2009, Curitiba. Anais ... Rio de Janeiro: ANPAD, 2009.

PAIVA, K. C. M. et al. Percepções de alunos e professores do curso de administração a respeito da educação à distância. Tourism \& Management Studies, v. 1, edição especial, p. 354-366, 2013.

PAIVA, K. C. M. et al. Competências e E-competências de professores de Administração. Revista Pretexto, v. 15, NE, p. 99-115, 2014.

PEREIRA, A.L.C.; SILVA, A. B. As Competências Gerenciais em Instituições Federais de Educação Superior. Cadernos EBAPE, v. 9, p. 627-647, 2011.

PERRENOUD, P. Desenvolver competências ou ensinar? A Escola que prepara para a vida. Porto Alegre: Penso, 2013.

POTGIETER, I; BASSON, J.; COETZEE, M. Management competencies for the development of heads of department in the higher education context: a literature overview. South African Journal of Labour Relations, v. 35, n.1, p. 81-103, 2011.

QUINN, R. E. et al. Competências Gerenciais: princípios e aplicações. Rio de Janeiro: Elsevier, 2003.

QUINTIERE, R. C.B.C.; VIEIRA, F. O.; OLIVEIRA, R.T.Q. Competências gerenciais: à beira da perfeição? O discurso de reitores de universidades federais do Rio de Janeiro. In: ENANPAD, 36., 2012, Rio de Janeiro. Anais... Rio de Janeiro: ANPAD, 2012.

RESENDE, E. O livro das competências: desenvolvimento das competências: a melhor autoajuda para pessoas, organizações e sociedade. Rio de Janeiro: Qualitymark, 2000.

RUAS, R. Gestão por competências: uma contribuição à estratégia das organizações. In: RUAS, R; ANTONELLO, C.S.; BOFF, L. H. Os novos horizontes da gestão: aprendizagem organizacional e competências. Porto Alegre: Bookman; 2005. p. 34-54.

SALLES, M. A. S. D.; VILLARDI, B. Q. O Desenvolvimento de Competências Gerenciais na Prática dos Gestores no Contexto de uma IFES Centenária. In: ENAPG, 6., 2014, Belo Horizonte. Anais... Rio de Janeiro: ANPAD, 2014.

SANTIAGO, R.; CARVALHO, T. Mudança no conhecimento e na profissão acadêmica em Portugal. Cadernos de Pesquisa, v. 41, n. 143, p. 402-426, 2011.

SANTIAGO, R. et al. Changing patterns in the middle management of higher education institutions: The case of Portugal. Higher Education, v. 52, p. 215-250, 2006.

SCHÖN, D. A. The Reflective Practitioner. London: Maurice Temple Smith, 1983. 
SILVA, M. G. R. Gestão universitária, competências gerenciais e seus recursos: um estudo de caso. In: EnANPAD, 27., 2003, Atibaia. Anais... Rio de Janeiro: ANPAD, 2003. SILVA, F. M. V.; CUNHA, C. J. C. A. A transição de contribuidor individual para líder: a experiência vivida pelo professor universitário. Revista GUAL, v. 5, n. 1, p. 145-171, 2012. SILVA, F. M. V. A transição para a gestão universitária: o significado das relações interpessoais. R. Adm. FACES, v. 11, n. 4, p. 72-91, 2012.

UNIVERSIDADE FEDERAL DO VALE DO SÃO FRANCISCO (UNIVASF). Plano de Desenvolvimento Institucional 2009-2014. Petrolina, 2014. Disponível em: $<$ http: / / www. pdi.univasf.edu.br/images/documentospdf/PDIUNIVASF2009_14.pdf > . Acesso em: $10 / 06 / 2014$.

VIEIRA, M. M. F. Por uma Boa Pesquisa (Qualitativa) em Administração. In: VIEIRA, M. M. M. F.; ZOUAIN, D. M. (Orgs). Pesquisa Qualitativa em Administração. Rio de Janeiro: FGV, 2004. p. 13-28.

WHITCHURCH, C. Reconstructing identities in higher education: The rise of "Third Space" professionals. London: Routledge, 2012.

WHITCHURCH, C. The Changing Roles and Identities of Professional Managers in UK Higher Education. Perspectives: Policy and Practice in Higher Education, v. 11, n .2, p. 53-60, 2007.

ZABALZA, M. O ensino universitário: seu cenário e seus protagonistas. Porto Alegre: Artmed, 2007. 


\section{DADOS DOS AUTORES}

\section{MILKA ALVES CORREIA BARBOSA^milka.correia@gmail.com Doutora em Administração pela UFPE}

Instituição de vinculação: Universidade Federal de Alagoas - Faculdade de Economia, Contabilidade e Administração

Maceió/AL - Brasil

Áreas de interesse em pesquisa: modelos de gestão em instituições de educação, gestão de pessoas, competências e papéis gerenciais, ensino e pesquisa em Administração.

*Av. Lourival Melo Mota, s/n Tabuleiro dos Martins Maceió/AL 57072-900

\section{JOSÉ RICARDO COSTA DE MENDONÇA jrcm@ufpe.br}

Doutor em Administração pela UFRGS

Instituição de vinculação: Universidade Federal de Pernambuco

Recife/PE - Brasil

Áreas de interesse em pesquisa: competências profissionais; metodologia de pesquisa qualitativa; ensino/aprendizagem e EAD; novas tecnologias para o ensino superior; políticas públicas para EAD; e gestão pública.

\section{FERNANDA RODA DE SOUZA ARAÚJO CASSUNDÉ fernanda.roda@univasf.edu.br \\ Doutora em Administração pela UFPE}

Instituição de vinculação: Universidade Federal do Vale do São Francisco

Petrolina/PE - Brasil

Áreas de interesse em pesquisa: relações de trabalho, representações sociais, impactos da nova morfologia do trabalho, sindicalismo e movimento operário; e Ensino e Pesquisa em Administração (competências profissionais e docentes; educação a distância; incorporação das TIC ao processo ensino-aprendizagem). 